\title{
Intestinal Lactase Synthesis during Postnatal Development in the Rat
}

\author{
MAUREEN M. JONAS, ${ }^{1}$ ROBERT K. MONTGOMERY, AND RICHARD J. GRAND \\ Division of Pediatric Gastroenterology and Nutrition. The Floating Hospital, New England Medical Center, \\ Boston, Massachusetts 02111 and Department of Pediatrics, Tufts University School of Medicine, \\ Boston, Massachusetts 02111
}

\begin{abstract}
To elucidate the mechanism of the developmental decline in intestinal lactase activity at weaning, we examined lactase synthesis in suckling and adult rats. Lactase was purified to homogeneity from pooled intestines of newborn rats and used to raise a monospecific antibody. Using this antibody, we developed a quantitative immunoprecipitation assay for lactase. Intestinal microvillus membrane proteins were labeled in 15-day and adult rats by intraluminal pulse-chase with ${ }^{3} \mathrm{H}$-leucine, and newly synthesized lactase quantified by immunoprecipitation. When lactase synthesis was expressed as the quantity of microvillus membrane lactase synthesized relative to total microvillus membrane protein synthesized, a significantly greater proportion of ${ }^{3} \mathrm{H}$-leucine incorporation into lactase was demonstrated in the suckling animals. No structural differences between newly synthesized suckling and adult lactase were observed when they were compared by SDSpolyacrylamide gel electrophoresis and fluorography. These data suggest that a change in the rate of lactase synthesis plays a role in the postweaning decline in enzyme activity. (Pediatr Res 19: 956-962, 1985)
\end{abstract}

Abbreviations

MVM, microvillus membrane

PBS, phosphate-buffered saline

TCA, trichloroacetic acid

DPM, disintegrations per minute

FI, fractional incorporation

PAGE, polyacrylamide gel electrophoresis

SDS, sodium dodecyl sulfate

Mammalian intestinal maturation is of crucial importance in adaptation from dependent neonatal to independent adult life. Lactase is the specific intestinal $\beta$-galactosidase catalyzing the hydrolysis of lactose, the principle carbohydrate present in milk, and is thus of prime importance during the suckling period, but is no longer required after weaning.

In rats, as in most other mammals, high levels of lactase are present in the intestinal mucosa at birth. Lactase activity decreases thereafter, so that by the time of weaning only low levels remain (1). Although this pattern suggests a direct diet-dependent mechanism for the weaning associated decline in lactase activity,

Received March 12, 1984: accepted April 26, 1985.

Address correspondence to Robert K. Montgomery. Ph.D. Division of Pediatric Gastroenterology and Nutrition. New England Medical Center, 171 Harrison Avenue, Box 383, Boston, MA 02111.

Supported by NIH Grants AM14523, AM32658, AM07333, AM07471, HD14498 and 1 p30 34928.

' Present address Department of Pediatrics, University of Miami School of Medicine, Miami, FL 33101. such a process has not been demonstrated in animal studies (24). Nevertheless, in adult rats, current evidence indicates a direct effect of diet and thyroxine on the enterocyte at all levels of the villus (5-7). The molecular mechanism for the developmental decline in intestinal lactase activity remains to be elucidated. Possible mechanisms include age-dependent differences in rates of transcription, enzyme synthesis, intracellular processing, transport, and degradation.

Difficulty with purification of lactase and its limited stability have previously precluded characterization of each of these processes, although descriptive studies of the enzyme, such as its chemical and physical properties, its distribution along the villus, and its biochemical action, have been carried out (8-10). Recently, purification of lactase from rat intestine has become technically feasible, and larger quantities of the enzyme can be prepared in a stable form and stored for prolonged periods (10). Using a modification of this technique, we have prepared a monospecific antibody to intestinal lactase as a probe for the biosynthesis of the enzyme.

The present study was undertaken to examine the relationship between the maturational decline in intestinal lactase activity and lactase synthesis rates in suckling and adult rats. Our results indicate that changes in rates of enzyme synthesis may be at least in part responsible for the postweaning decline in lactase levels.

\section{MATERIALS AND METHODS}

Experiments were performed using adult ( 6 to $8 \mathrm{wk}$ ) male and 15-day male and female albino rats (Charles River Breeding Laboratories, Wilmington, MA). Based on preliminary experiments, it was ascertained that 15-day animals were the youngest suckling rats in which the labeling experiments we devised could be reproducibly performed. The 15-day animals were allowed to suckle ad libitum, and the adult rats were fed standard laboratory Chow (Purina, St. Louis, MO) and water ad libitum. All animals were housed in a constant temperature and humidity environment, on a 12-h light-dark cycle. All time frames for animal procedures were kept constant throughout the study. In the 15day rats the entire small intestine, and in the adult rats the middle third of the small intestine was used. With the animals under light ether anesthesia, the segment of intestine to be used was identified, the proximal end was ligated, and enough warm PBS was administered via a plastic catheter to fill the required segment (1.5 $\mathrm{ml}$ in 15-day animals, $10 \mathrm{ml}$ in adult animals). The segment was then filled with $\sim 95 \mu \mathrm{Ci} / \mathrm{g}$ mucosa of ${ }^{3} \mathrm{H}$-leucine (40 to 60 $\mathrm{mCi} / \mathrm{mmol}$, New England Nuclear, Boston, MA) in PBS. The radioisotope was allowed to remain in the intestinal lumen for $20 \mathrm{~min}$; there was no observable loss of volume from the lumen during this period. This was followed by a chase of $5 \mathrm{mM}$ cold leucine in PBS. All animals except those used for 30-min labeling experiments were then allowed to recover from anesthesia. At appropriate times after the start of labeling $(1 / 2,1,2$, and $4 \mathrm{~h}$ ), 
animals were sacrificed, and the perfused segments were quickly excised and rinsed with iced $0.9 \%$ saline solution. Mucosa was scraped and either frozen immediately or homogenized in 100 volumes $2 \mathrm{mM}$ Tris, $50 \mathrm{mM}$ mannitol, $\mathrm{pH} \mathrm{7.2,} \mathrm{and} \mathrm{frozen.}$

Enzyme and protein assays. The disaccharidases were assayed according to a modification by Grand et al. (11) of the procedure of Messer and Dahlqvist (12). Substrate for the lactase assay contained $0.2 \mathrm{mM}$ PCMB as inhibitor of nonspecific $\beta$-galactosidase. Protein was assayed according to Lowry et al. (13) using bovine serum albumin as the standard.

Preparation of $M V M$. MVM were prepared from mucosa homogenized in Tris-mannitol buffer by the calcium precipitation method of Kessler et al. (14). Purification of MVM by this method was monitored by enrichment of lactase activity over that in the original homogenates. The specific activity of lactase increased 20-fold in preparations from suckling animals and 18fold in preparations from adult animals.

$T C A$ precipitation of homogenates and $M V M$. Aliquots of the original homogenates in Tris-mannitol buffer and of MVM were rapidly added to equal volumes of $20 \% \mathrm{TCA}$, mixed by vortexing, kept overnight at $4^{\circ} \mathrm{C}$, and processed for assay of protein content and radioactivity as previously described $(15,16)$.

Immunoprecipitation techniques. To measure the incorporation of radioactivity into newly synthesized MVM lactase, a quantitative immunoprecipitation assay was developed. Rat intestinal lactase purified to electrophoretic homogeneity was prepared from newborn rats by the method of Tsuboi et al. (10), which yielded a 150 -fold purification. Further purification was obtained by polyacrylamide disc gel electrophoresis in a nondenaturing system on which lactase migrated as a single band. The lactase band was identified by correlation of enzyme activity and Coomassie Blue staining and was sliced from untreated gels using the calculated $R_{f}$ value. Gel slices were homogenized in equal volumes of complete Freund's adjuvant, and this preparation was injected into a rabbit (three subcutaneous injections at 2-wk intervals). After an additional $2 \mathrm{wk}, \mathrm{IgG}$ was purified from antiserum by chromatography on Whatman DEAE-cellulose. The resulting antibody was shown to be monospecific by radial diffusion and by immunoelectrophoresis (Fig. 1).

Quantitative immunoprecipation curves were constructed to identify the equivalence point of the lactase-antilactase reaction. Optimal conditions were initially established using variable quantities of lactase and antilactase IgG. Equivalence was reached with $7.0 \mu \mathrm{g}$ antilactase $\mathrm{IgG}$ per mU lactase activity (Fig. 2). Quantitative immunoprecipitation using this antibody and purified lactase resulted in precipitation of greater than $98 \%$ of the lactase activity. This antibody was used in all subsequent experiments.

For immunoprecipitation, MVM preparations were homogenized in a small ground-glass homogenizer for $90 \mathrm{~s}$. Lubrol-PX (Sigma Chemical Co., St. Louis, MO) was added to a final concentration of $0.6 \%$. After $1 \mathrm{~h}$ at $23^{\circ} \mathrm{C}$, the preparation was centrifuged at $27,000 \times g$ for $30 \mathrm{~min}$. The clarified supernatants

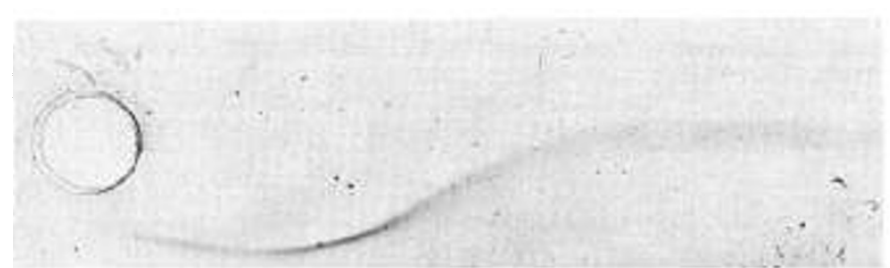

Fig. 1. Monospecificity of $\operatorname{IgG}$ preparation. A sample of detergent solubilized MVM was placed in well at left and electrophoresed for $2 \mathrm{~h}$. Troughs were cut at top and bottom, filled with purified lactase and antilactase IgG, respectively, and incubated overnight. The single arc of precipitation at the bottom demonstrates that the IgG reacts with a single antigen from the MVM, while the continuity of this line with that formed by the purified lactase and antilactase demonstrates the identity of the MVM antigen precipitated.

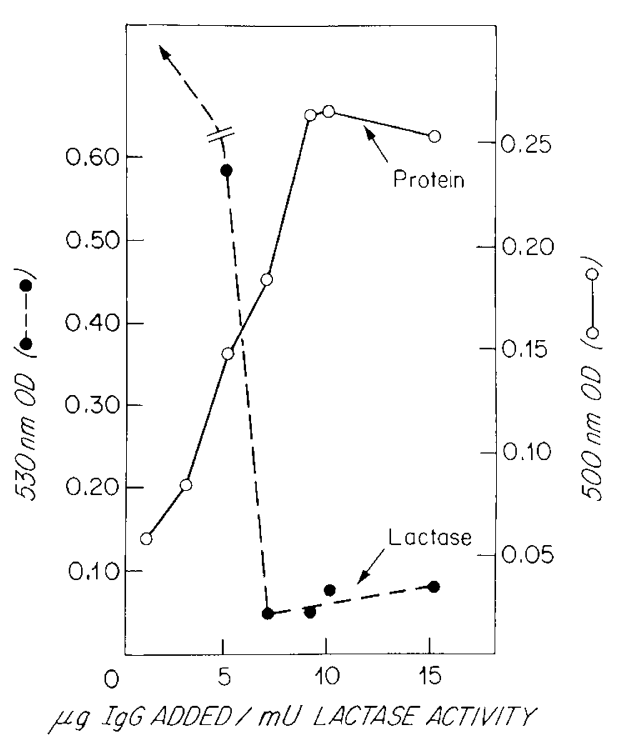

Fig. 2. Immunoprecipitation curve of lactase and antilactase $\operatorname{IgG}$. The equivalence point was identified at $7.0 \mu \mathrm{g} \mathrm{IgG}$ per $\mathrm{mU}$ lactase activity. Protein refers to the assay of the immunoprecipitate: lactase refers to the residual lactase activity in the supernatant after centrifugation of the immunoprecipitate as described in "Materials and methods."

were then employed in the immunoprecipitation assay using the antigen and antibody ratios described above. Reaction mixtures were incubated first at $37^{\circ} \mathrm{C}$ for $1 \mathrm{~h}$ and then at $4^{\circ} \mathrm{C}$ for 18 to $72 \mathrm{~h}$. Precipitates were recovered by centrifugation at $12,800 \times$ $g$ for $5 \mathrm{~min}$ in an Eppendorf Microfuge (Brinkman Instruments, Inc., Westbury, NY), washed once in PBS, dissolved in $0.1 \mathrm{~N}$ $\mathrm{NaOH}$ and aliquots assayed for protein content and radioactivity.

Nonspecific precipitation of radioactivity was determined frorn reaction mixtures containing solubilized MVM fractions, purified ovalbumin (OVA), and rabbit antiovalbumin (generously provided by Drs. Gabriel Goldberger and Harvey Colten, Division of Cell Biology, Children's Hospital, Boston, MA). Immunoprecipitates from these mixtures were treated exactly as described above. Radioactivity precipitated by the OVA-anti OVA complex was not more than $5 \%$ of the radioactivity of the original precipitate.

Liquid scintillation counting. Radioactivity of the immunoprecipitates, the TCA-precipitated protein from homogenates and MVM fractions, and the TCA-soluble fractions was determined in a liquid scintillation spectrometer model LS 8000 (Beckman Instrument Co., Irvine, CA). DPM were calculated using a commercial quench series (New England Nuclear, Boston, MA) and the Compton edge shift measure of counting efficiency (17).

SDS-Polyacrylamide gel electrophoresis. Immunoprecipitates of labeled MVM lactase were prepared as described above. Precipitates were solubilized by heating to $100^{\circ} \mathrm{C}$ in a boiling water bath for $5 \mathrm{~min}$ in $0.05 \mathrm{M}$ Tris buffer containing $1 \%$ SDS and $5 \% \beta$-mercaptoethanol. All other samples were solubilized in the same manner. Electrophoresis was performed on SDSpolyacrylamide slab gels consisting of a $3 \%$ stacking gel and a $7.5 \%$ separating gel made according to the method of Neville (18). After running, gels were simultaneously fixed and stained in a $0.006 \%$ solution of Coomassie Blue in acetic acid, methanol, and water.

Gels were prepared for fluorography according to the method of Laskey and Mills (19), except that En ${ }^{3}$ Hance (New England Nuclear) was used as the scintillant. Gels were fixed, and the excess stain was removed. Gels were then soaked in $E^{3}{ }^{3}$ Hance, washed in tap water, and dried on filter paper backing. The dried gels were enclosed in an x-ray cassette against a sheet of preflashed Kodak X-Omat film and stored in a $-70^{\circ} \mathrm{C}$ freezer for $4 \mathrm{wk}$. 


\section{RESULTS}

Labeling of $M V M$ proteins and $M V M$ lactase. Radiolabeling of total MVM protein was examined in TCA precipitates of the microvillus membranes. Figure 3 left depicts results of the timed labeling of total MVM proteins in the 15-day rats. There was a linear increase in the specific radioactivity of MVM proteins from $18,000 \mathrm{DPM} / \mathrm{mg}$ at $1 / 2 \mathrm{~h}$ to $47,000 \mathrm{DPM} / \mathrm{mg}$ at $4 \mathrm{~h}$ after labeling $(p<0.005)$. In adult animals, a similar labelling pattern was observed: $65,000 \mathrm{DPM} / \mathrm{mg}$ at $1 / 2 \mathrm{~h}$ and $212,000 \mathrm{DPM} / \mathrm{mg}$ at $4 \mathrm{~h}(p<0.025)$.

Alpers and Thier (20) have demonstrated in rat jejunal slices that exogenously administered amino acids enter an intracellular pool before being incorporated into intestinal proteins. In addition, with an in vivo system and a double-isotope technique, they demonstrated that the radioactivity in intestinal protein, expressed as the ${ }^{3} \mathrm{H} /{ }^{14} \mathrm{C}$ ratio, was identical to that of the intracellular soluble pool and different from that of the lumen and the blood. Thus, in vitro and in vivo the intracellular pool controls the entry of radioactive precursors into MVM protein. Figure 3 right shows the changes in radioactivity with time in the TCAsoluble fraction of mucosal homogenates from our experiments in the 15-day rats. There was a steady decrease over time, reflecting uptake of labeled precursor into protein. A small increase occurred at $4 \mathrm{~h}$ which may have been due to protein degradation and release of ${ }^{3} \mathrm{H}$-leucine into the pool. In adult animals, radioactivity in the TCA-soluble fraction also decreased with time, from $7064 \mathrm{DPM} / \mathrm{ml}$ at $1 / 2 \mathrm{~h}$ to $4649 \mathrm{DPM} / \mathrm{ml}$ at $4 \mathrm{~h}$ $(p<0.01)$. Thus, in both suckling and adult animals, the decrease in ${ }^{3} \mathrm{H}$-leucine in the intracellular pool occurs concomitantly with the increase in MVM protein labeling. This pattern is indicative of a precursor-product relationship and is consistent with the findings of Alpers and Thier (20). In addition, the time course of the MVM protein labeling suggests equilibration between the extracellular and intracellular pools by $1 / 2 \mathrm{~h}$ after labeling and is similar in the suckling animals to that previously described for adult rats (20).

The time course of radioactive labeling of lactase immunoprecipitated from MVM preparations from the 15-day rats is shown in Figure 4. Substantial incorporation of ${ }^{3} \mathrm{H}$-leucine into lactase was accomplished by $1 / 2 \mathrm{~h}$ after labeling, with an increase in specific radioactivity of lactase from $23,600 \mathrm{DPM} / \mathrm{mg}$ at $2 \mathrm{~h}$ to
$59,400 \mathrm{DPM} / \mathrm{mg}$ at $4 \mathrm{~h}$. Comparable values from experiments with adult rats showed a rise from $45,600 \mathrm{DPM} / \mathrm{mg}$ at $1 / 2 \mathrm{~h}$ to $235,000 \mathrm{DPM} / \mathrm{mg}$ at $4 \mathrm{~h}(p<0.025)$. Although these data show significantly greater incorporation of ${ }^{3} \mathrm{H}$-leucine into MVM lactase in adult than in suckling animals, incorporation of radioactivity into total mucosal protein (data not shown) as well as total MVM protein, as shown above, was also greater in adult animals. Total MVM protein in suckling ( 10 day) rats has been found to be half that found in adult animals (10). Accordingly, incorporation into MVM lactase was expressed in each animal and age group as a fraction of incorporation into total MVM protein.

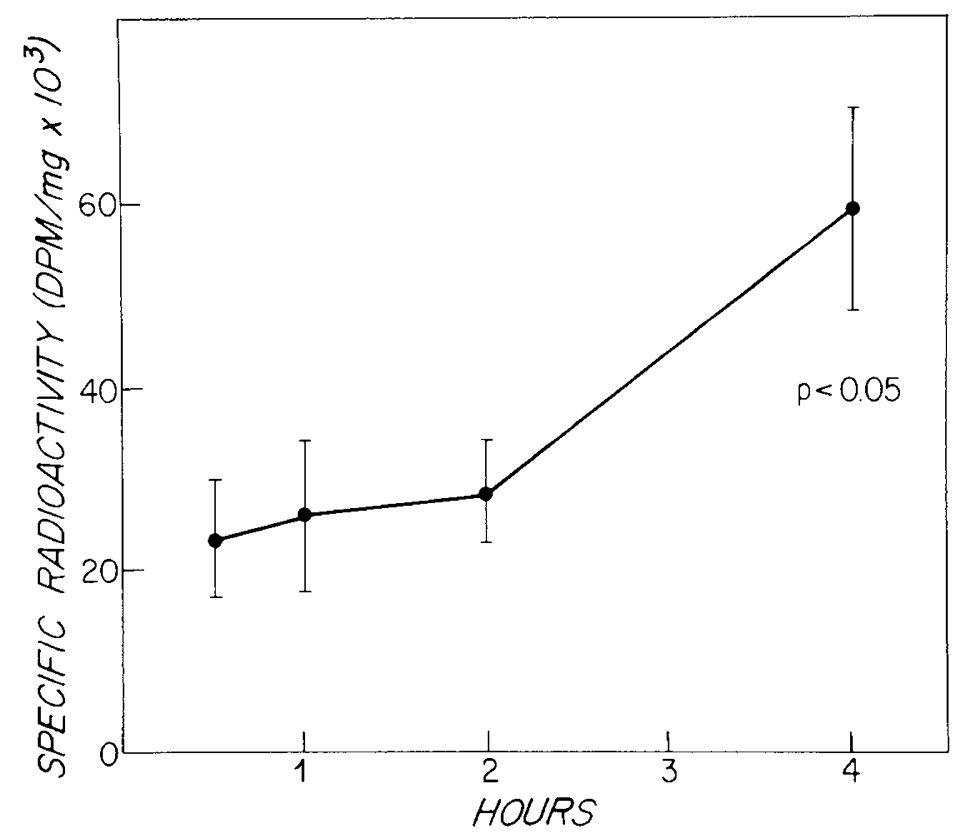

Fig. 4. Incorporation of ${ }^{3} \mathrm{H}$-leucine into MVM lactase in 15-day rats at $1 / 2,1,2$, and $4 \mathrm{~h}$ after labeling. Lactase was immunoprecipitated from MVM preparations as described in "Materials and methods," and the specific radioactivity was measured. Each point represents six animals and is expressed as the means \pm SEM.
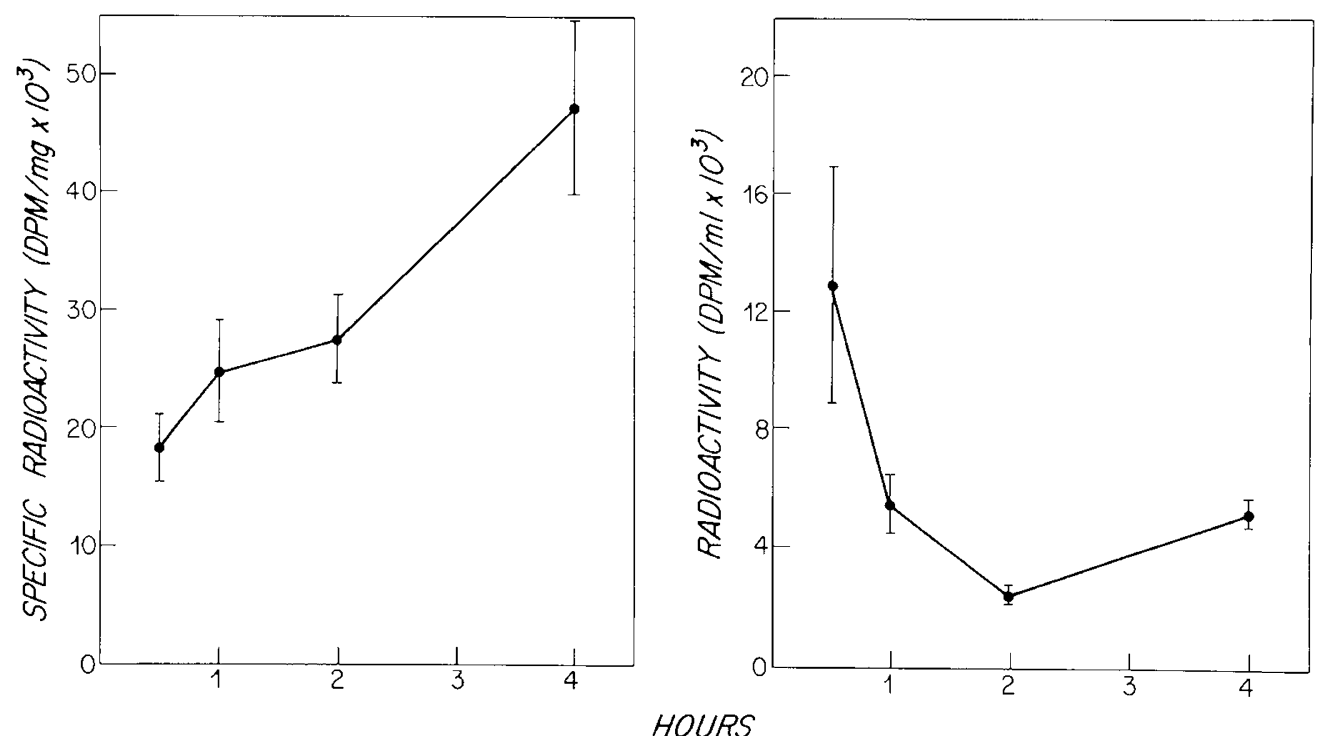

Fig. 3. Leffi, incorporation of ${ }^{3} \mathrm{H}$-leucine into total MVM protein in 15 -day rats at $1 / 2,1,2$, and $4 \mathrm{~h}$ after labeling. Protein was precipitated from MVM preparations with TCA, and the specific radioactivity was measured as described in "Materials and methods." Right, radioactivity of the TCA-soluble fraction of mucosal homogenates from 15-day rats at 1/2, 1,2, and $4 \mathrm{~h}$ after labeling. In both parts of Figure 3, each point represents data from six animals and is expressed as the mean \pm SEM. 
Fractional incorporation of label into MVM lactase. Fractional incorporation was calculated to examine the labeling of lactase relative to labeling of all MVM protein, as shown in the following formula and published previously (15):

$$
\mathrm{FI}=\frac{\mathrm{mg} \text { lactase in } \mathrm{MVM} \times \mathrm{DPM} / \mathrm{mg} \text { lactase }}{\mathrm{mg} \text { protein in } \mathrm{MVM} \times \mathrm{DPM} / \mathrm{mg} \text { protein }} \times 100
$$

FI corrects for individual or age-related variability in mucosal surface area exposed to radioactive label, for potential variability in ${ }^{3} \mathrm{H}$-leucine dosage per gram mucosa, and for differences in efficiency in protein labeling between the two groups. It also corrects for differences in the absolute number of lactase molecules present or synthesized over time which may be much greater in adult than suckling animals secondary to differences in the total number of enterocytes available (21) and total MVM protein content (10) in the experimental loop of bowel.

Specific enzyme activity of lactase in solubilized MVM preparations was $1.06 \pm 0.14 \mathrm{U} / \mathrm{mg}$ in 15-day rats and $0.36 \pm 0.03$ $\mathrm{U} / \mathrm{mg}$ in adult rats $(p<0.0005)$. Fractional incorporation of radioactive label into lactase in the 15-day rats as contrasted with adult rats is shown in Figure 5. At each time point after labeling, FI into lactase was significantly greater in the suckling (4.5 to $10 \%)$ than the adult $(0.8$ to $2.2 \%)$ animals, indicating greater differential incorporation into lactase. Again, substantial synthesis of lactase by $1 / 2 \mathrm{~h}$ after labeling was noted in both age groups. In adult rats, the percentage of label that was incorporated into lactase at each time point was constant. However, as shown in Figure 5 , the 15-day rats demonstrated a larger proportion of incorporation into lactase at $2 \mathrm{~h}$ relative to the other time points. Differential rates of turnover of MVM proteins in suckling rats have been previously demonstrated by Seetharam et al. (22), with higher rates of MVM protein turnover in suckling than in adult animals. Differences in fractional incorporation into lactase with time may reflect a differential turnover rate of lactase compared to other MVM proteins, since this value represents relative content of ${ }^{3} \mathrm{H}$-leucine at each time point. Nevertheless, the significantly greater fractional incorporation into MVM lactase in 15-day rats than in adult rats was consistent.

Fractional incorporation of label into MVM sucrase. Fifteen days is a critical time in the developmental pattern of MVM disaccharidases. During this period, intestinal lactase activity decreases and sucrase-isomaltase activity rises, reaching adult levels by the time of weaning at 21 days $(1,23)$. For this reason, and in order to corroborate our method and further establish the validity of the fractional incorporation calculation as independent of enzyme specific activity, rates of sucrase-isomaltase synthesis were estimated from the same labeling experiments, using the same MVM preparations. For these experiments, monospecific antisucrase $\mathrm{IgG}$ was used in the immunoprecipitation assay as previously described $(15,24)$.

Specific enzyme activity of sucrase in solubilized MVM preparations was $0.12 \pm 0.02 \mathrm{U} / \mathrm{mg}$ in 15 -day rats and $1.17 \pm 0.08$ $\mathrm{U} / \mathrm{mg}$ in adult rats $(p<0.0005)$. Fractional incorporation of radioactive label into sucrase-isomaltase ranged from $2.1 \pm 0.9$ to $4.2 \pm 4.4 \%$ in the suckling animals and $2.0 \pm 0.4$ to $7.2 \pm$ $2.0 \%$ in the adult animals. Overall, there was no significant difference between the two age groups. The presence of active sucrase-isomaltase radiolabeling in the 15-day animals reflects the initiation of sucrase synthesis that occurs at this age (22). The finding that fractional incorporation into sucrase-isomaltase in 15-day rats is comparable to that found in adults indicates that fractional incorporation does not simply parallel enzyme activity. FI into sucrase-isomaltase was not different in the two age groups, but enzyme specific activity was 10 -fold greater in the adult animals.

Electrophoretic analysis of $M V M$ lactase. Lactase immunoprecipitated as described above was examined by PAGE in SDS (17). Figure 6 shows the result of a representative experiment. The stained gel is shown in lanes 1 through 4 , and the fluorogram of this gel is shown in lanes 5 and 6 . Using a standard curve calculated from molecular weight standards (lane 1) the molecular weight of MVM lactase was estimated at approximately 127,000 daltons. Lane 2 displays a total adult MVM preparation. This contains a major protein band which migrates to the same position as the immunoprecipitated MVM lactase seen in lanes 3 and 4 (from adult and suckling rats, respectively). In addition, lanes 3 and 4 demonstrate that the immunoprecipitated MVM lactase from adult and 15-day rats comigrate. The fluorogram of the MVM preparation, lane 5, demonstrates evidence for incorporation of radioactivity into many constituent proteins at $2 \mathrm{~h}$. Lane 6 , the fluorogram of the immunoprecipitated lactase from

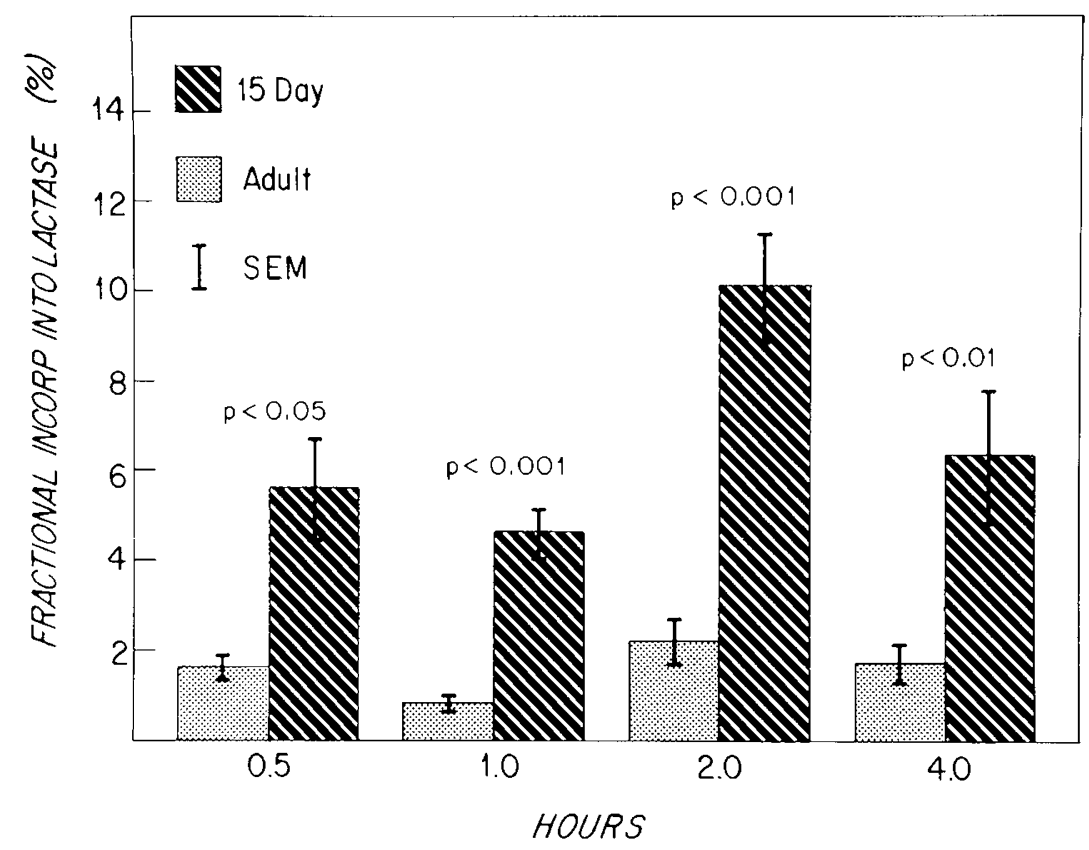

Fig. 5. Fractional Incorporation of ${ }^{3} \mathrm{H}$-leucine into MVM lactase in adult and 15 -day rats at $1 / 2,1,2$, and $4 \mathrm{~h}$ after labeling. FI, as calculated by the formula shown in the text, represents the percentage of ${ }^{3} \mathrm{H}$-leucine incorporated into lactase relative to that into total MVM protein. The $p$ values shown are for the difference in FI into lactase between adult and 15-day rats at each time point. 


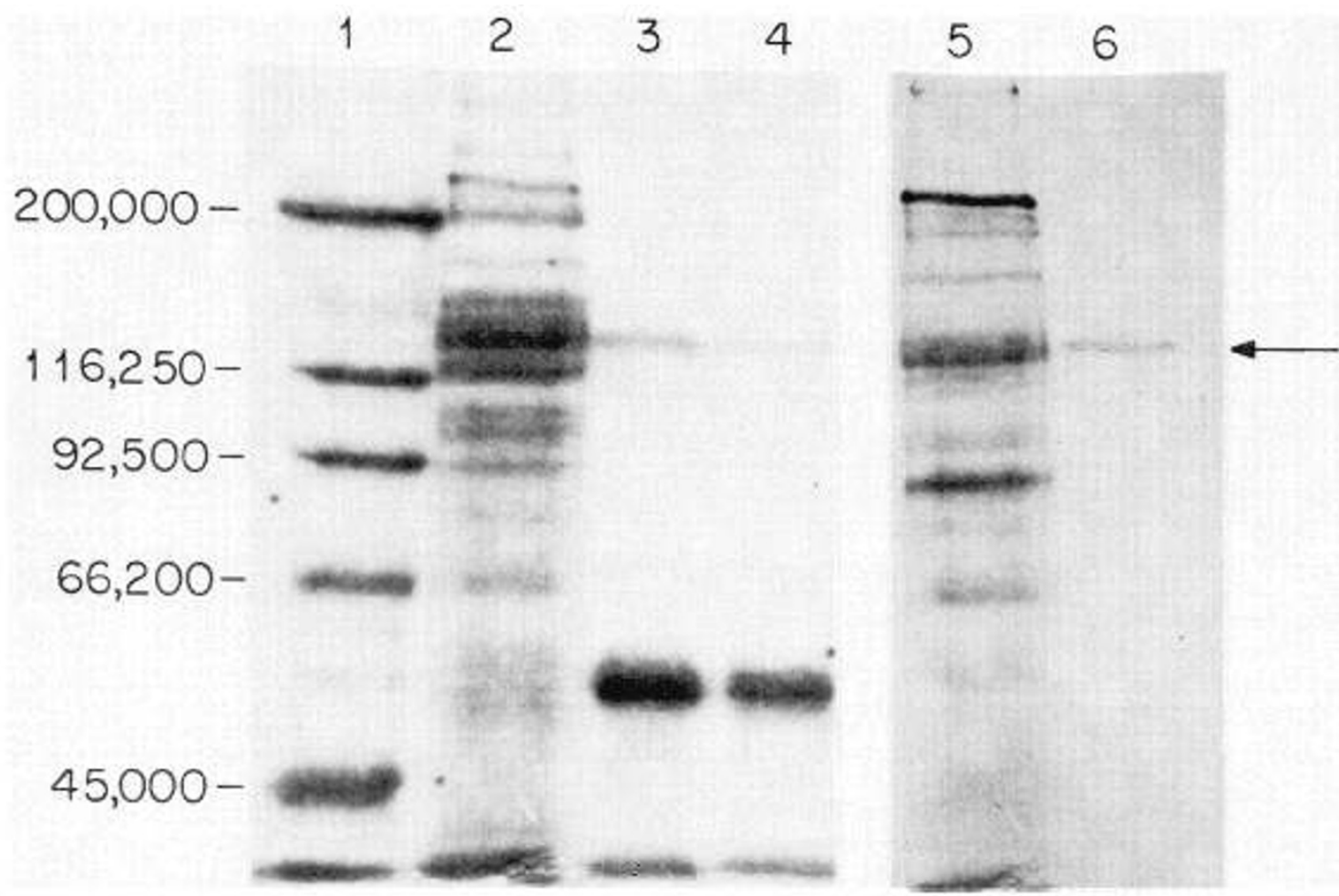

Fig. 6. SDS-PAGE and fluorography of MVM lactase. Samples were electrophoresed on a polyacrylamide slab gel consisting of $3 \%$ stacking and $7.5 \%$ separating components, as described in "Materials and methods." Lanes $1-4$ are stained with Coomassie blue. Lane 1 contains standards with the molecular weights indicated. Lane 2 contains a total MVM preparation from an adult rat. Lanes 3 and 4 contain lactase immunoprecipitated from adult and 15-day MVM preparations, respectively. This gel was processed for fluorography as described in "Materials and methods." Lane 5 displays the fluorogram of the MVM preparation and lane 6 the fluorogram of the immunoprecipitated MVM lactase (arrow).

this preparation, shows that the newly synthesized lactase is found in a major band comigrating with the lactase band in the stained gel (lanes 3 and 4).

\section{DISCUSSION}

Although there have been many studies over the past $30 \mathrm{yr}$ attempting to elucidate the mechanisms controlling intestinal maturation, there are few data concerning specific molecular processes involved. We have used a monospecific antibody to intestinal lactase to develop a quantitative immunoprecipitation assay for newly synthesized MVM lactase in pulse-chase radiolabeling experiments. When lactase synthesis was expressed as amount of lactase synthesized relative to total MVM protein synthesized, a substantial difference was found between 15-day and adult rats. Indeed, fractional incorporation into lactase was much greater in the 15-day animals at all time points studied. Thus, kinetic differences in uptake of amino acid precursors or protein degradation were not entirely responsible for the changes observed. In addition, as shown by the studies using SDS-PAGE, the MVM lactase from suckling and adult rats appears to be structurally identical.

The finding of significant quantities of newly synthesized lactase in the microvillus membranes of both 15-day and adult rats at $1 / 2 \mathrm{~h}$ after labeling suggests rapid synthesis and intracellular processing of this enzyme by the epithelial cells. A comparable time course was observed by Cezard et al. (25) in studies of the kinetics of adult MVM sucrase-isomaltase synthesis using a similar intraluminal pulse-chase technique. Although intracellular sucrase-isomaltase was more heavily labeled than MVM sucrase-isomaltase during the $1 \mathrm{st} \mathrm{h}$ after labeling, there was still easily measurable incorporation of ${ }^{3} \mathrm{H}$-leucine into MVM sucrase-isomaltase at 10 to $30 \mathrm{~min}$ after labeling. Thus, enterocytes are capable of rapid synthesis and insertion of disaccharidases into the MVM.
Since these pulse-chase labeling experiments were not done on single cells in a uniform cell cycle, but rather in an in vivo system with some uncontrollable variables such as surface area of mucosa and number of enterocytes exposed to the radioactive label, it is not possible to extrapolate directly from specific radioactivity of MVM lactase to a lactase synthesis rate. For this reason, fractional incorporation of ${ }^{3} \mathrm{H}$-leucine into MVM lactase was calculated, and the labeling of MVM lactase in each animal was expressed as a percentage of the total MVM protein synthesized in the same animal during experimental time period. This measurement allowed comparisons between different age populations of animals, correcting for variation in animal size, length, and surface area of bowel included in the experimental loop, as well as individual efficiency of total protein synthesis. Fractional incorporation was also demonstrated to be not simply a reflection of enzyme activity. The experiments with sucrase-isomaltase clearly showed a divergent pattern between the two functions; fractional incorporation into sucrase-isomaltase was similar in suckling and adult animals although enzyme specific activity was 10 -fold greater in the adult rats. Thus, fractional incorporation is an independent expression of synthesis of a particular protein, in this case lactase, as a proportion of total protein synthesis during a given time.

As described, examination of MVM lactase from the 15-day and adult rats by SDS-PAGE and fluorography revealed a major protein band of newly synthesized enzyme. Previous workers have described various electrophoretic patterns of rat lactase under varying experimental conditions $(10,26,27)$. Birkenmeier and Alpers (26) found five protein bands by electrophoresis of rat lactase under nonreducing, nondenaturing conditions, with a major protein band having a molecular weight of 132,000 . Skovbjerg et al. (28) reported that human lactase examined by SDS-PAGE consisted of a single protein band with a molecular weight estimated as 160,000 . In our experiments, immunoprecipitated lactase from detergent-solubilized MVM, run under 
denaturing conditions, was seen as a major protein band with a molecular weight of approximately 127,000 daltons. This was true whether the MVM were obtained from the middle one-third of the small intestine of adult rats or the entire small intestine of the suckling rats.

Numerous workers have studied lactase enzyme activity in animals at or around the time of weaning. The developmental pattern of lactase activity was elucidated by Doell and Kretchmer in 1962 (29). They found rapid increases in intestinal lactase in rats and rabbits in the last several days of gestation, a peak at the time of birth and gradual decline to adult levels at the time of weaning. Rubino et al. (1) made similar observations and, although no mechanism for these changes was postulated, they alluded to the coincidence of the decline in lactase activity and the weaning period. Since these observations were made, several mechanisms have been suggested to account for the decrease in lactase activity, including dietary adaptation, hormonal control, and changes in enterocyte migration rates.

Dietary adaptation has been extensively examined as a stimulus for the decrease in intestinal lactase activity. As early as 1907 , experiments in rats and rabbits demonstrated no correlation between dietary lactose and lactase activity (4). More recently, Bolin et al. $(30,31)$ have demonstrated a persistence of lactase activity in adult rats after 5 to $10 \mathrm{wk}$ of very high lactose intake, but these elevated lactase levels were transient and represented increases of 50 to $100 \%$ over controls, whereas the decline from infancy to adulthood is normally on the order of 5fold (1). In addition, in experiments involving implantation of isografts of fetal mouse or rat intestine into adult animals, the graft demonstrated the same lactase developmental pattern as the normal intestine after birth, although it was never exposed to lactose $(2,32)$. These findings argue against adaptation to dietary lactose as a controlling factor in decreasing lactase levels at weaning.

Dietary manipulation, however, led to significant insight into a completely different control mechanism regulating intestinal maturation. In a series of experiments involving the enforcement of premature weaning (33), adrenalectomy (34), and pituitary ablation with exogenous hormone replacement (35), a combined or interdependent effect of glucocorticoids and thyroxine on the maturational patterns of intestinal enzymes, such as alkaline phosphatase and lactase, was demonstrated. The mechanism by which these hormones have their effects remains elusive (36), but may involve changes in lactase synthesis rate.

It has been known for some time that enterocytes mature both morphologically and biochemically while migrating from the crypts to the villi $(37,38)$. In 1980 , Boyle et al. (9) demonstrated that there was differential lactase activity among cells along the length of the villus, with lactase activity increasing as the cells matured. Tsuboi et al. (39) confirmed this pattern, then demonstrated acceleration in cell migration rates from crypt to villus as animals matured from 16 to 21 days of age. From these data they postulated that the mechanism for the decrease in lactase at weaning was the accelerated turnover and loss of the mature cells which contained the most lactase. These phenomena may be temporally parallel, but causally unrelated, since specific activities of sucrase-isomaltase, maltase, and alkaline phosphatase increase over the same time period (3); this pattern is not explicable by their model.

We have demonstrated that newly synthesized intestinal lactase can be labeled and quantified by an intraluminal pulse-chase technique and specific immunoprecipitation of the enzyme. The labeling of the MVM lactase relative to labeling of total MVM protein, i.e. fractional incorporation into lactase, was significantly greater in suckling than adult rats, and was not simply a reflection of enzyme specific activity. There is no structural difference in lactase between suckling and adult animals. These data suggest that changes in the rate of intestinal lactase synthesis may be at least in part responsible for the postweaning decline in lactase activity.
Acknowledgments. The authors thank Ms. Linda Huffer and Ms. Mariana Sybicki for expert technical assistance.

\section{REFERENCES}

1. Rubino A, Zimbalatti R, Auricchio S 1964 Intestinal disaccharidase activities in adult and suckling rats. Biochim Biophys Acta 92:305-311

2. Ferguson A, Gerskowitch VP, Russell RI 1973 Pre and postweaving disaccharidase patterns in isografts of fetal mouse intestine. Gastroenterology 64:292297

3. Goldstein R, Klein T, Freier S, Menozel J 1971 Alkaline phosphatase and disaccharidase activities in the rat intestine from birth to weaning. 1. Effect of diet on enzyme development. Am J Clin Nutr 24:1224-1231

4. Plimmer RHA 1906 On the presence of lactase in the intestine of animals and on the adaptation of the intestine to lactose. J Physiol (Lond) 35:20-31

5. Boyle JT, Kelly K, Drulich L, Koldovsky O 1982 Site of thyroxine-evoked decrease of jejunal lactase in the rat. Am J Physiol 243:G359-G364

6. Goda T, Yamada K, Bustamante S, Koldovsky O 1983 Dietary-induced rapid decrease of microvillar carbohydrase activity in rat jejunoileum. Am $J$ Physiol 245:G418-G423

7. Goda T, Bustamante S, Thornburg W, Koldovsky O 1984 Dietary-induced increase in lactase activity and in immunoreactive lactase in adult rat jejunum. Biochem J 221:261-263

8. Alpers DH 1969 Separation and isolation of rat and human intestinal $\beta$ galactosidases. J Biol Chem 244:1238-1246

9. Boyle JT, Celano P, Koldovsky O 1980 Demonstration of a difference in expression of maximal lactase and sucrase activity along the villus in the adult rat jejunum. Gastroenterology 79:503-507

10. Tsuboi KK, Schwartz SM, Burrill PH, Kwong LK, Sunshine P 1979 Sugar hydrolases of the infant rat intestine and their arrangement on the brush border membrane. Biochim Biophys Acta 554:234-248

11. Grand RJ, Chong DA, Isselbacher KJ 1972 Intracellular processing of disaccharidases. The effect of actinomycin D. Biochim Biophys Acta 261:341352

12. Messer M, Dahlquist A 1966 A one-step ultramicro method for the assay of intestinal disaccharidases. Anal Biochem 14:376-392

13. Lowry OH, Rosebrough NJ, Farr AL. Randall RJ 1951 Protein measurement with the Folin phenol reagent. J Biol Chem 193:265-275

14. Kessler M. Acuto O. Storelli C, Murer H, Muller M. Semenza G 1978 A modifed procedure for the rapid preparation of efficinetly transportirg vesicles from small intestinal brush border membrane. Biochim Biophys Acta 506:136-154

15. Grand RJ, Montgomery RK, Perez A 1985 Synthesis and intracellular processing of sucrase-isomaltase in rat jejunum. Gastroenterology 88:531-538

16. Siekevitz P 1952 Uptake of radioactive alanine in vitro into the proteins of rat liver fractions. J Biol Chem 195:549-565

17. Horrocks D 1974 Applications of Liquid Scintillation Counting. Academic Press, New York, p 217

18. Neville DM 1971 Molecular weight determination of proteindodecyl sulfate complex by gel electrophoresis in a discontinuous buffer system. J Biol Chem 246:6328-6334

19. Laskey RA, Mills AD 1975 Quantitative film detection of ${ }^{3} \mathrm{H}$ and ${ }^{14} \mathrm{C}$ in polyacrylamide gels by fluorography. Eur J Biochem 56:335-341

20. Alpers DH. Thier SO 1972 Role of the free amino acid pool of the intestine in protein synthesis. Biochim Biophys Acta 262:535-545

21. Altmann GG, Enesco M 1967 Cell number as a measure of distribution and renewal of epithelial cells in the small intestine of growing and adult rats. Am J Anat 121:319-336

22. Seetharam B, Yeh KY, Alpers DH 1980 Turnover of intestinal brush-border proteins during postnatal development in rat. Am J Physiol 234:G524-G531

23. Henning SJ 1978 Plasma concentrations of total and free corticosterone during development in the rat. Am J Physiol 235:E451-E456

24. Montgomery RK. Sybicki MA. Forcier AG, Grand RJ 1981 Rat intestinal microvillus membrane sucrase-isomaltase is a single high molecular weight protein and fully active enzyme in the absence of luminal factors. Biochim Biophys Acta 661:346-349

25. Cezard JP, Conklin KA, Das BC, Gray GM 1979 Incomplete cellular forms of intestinal surface membrane sucraseisomaltase. J Biol Chem 254:8969-8975

26. Birkenmeier E. Alpers DH 1973 Enzymatic properties of rat lactase-phlorizin hydrolase. Biochim Biophys Acta 350:100-112

27. Cousineau J, Green JR 1980 Isolation and characterization of the proximal and distal forms of lactase-phlorizin hydrolase from the small intestine of the suckling rat. Biochem Biophys Acta 615:147-157

28. Skovbjerg H. Sjostrom H, Noren O 1981 Purification and characterization of amphiphilic lactase/phlorizin hydrolase from human small intestine. Eur $\mathrm{J}$ Biochem 114:653-661

29. Doell RG, Kretchmer N 1962 Studies of small intestine during development 1. Distribution and activity of $\beta$-galactosidase. Biochim Biophys Acta 62:353-362

30. Bolin TD, McKern A, Davis AE 1971 The effect of diet on lactase activity in the rat. Gastroenterology 60:432-437

31. Bolin TD, Pirola RC, Davis AE 1969 Adaptation of intestinal lactase in the rat. Gastroenterology 57:406-409

32. Montgomery RK. Sybicki MA, Grand RJ 1981 Autonomous biochemical and morphological differentiation in fetal rat intestine transplanted at 17 and 20 days of gestation. Dev Biol 87:76-84 
33. Moog F 1951 The functional differentiation of the small intestine. II The differentiation of alkaline phosphomonoesterases in the duodenum of the mouse. J Exp Zool 118:187-205

34. Moog F 1953 The functional differentiation of the small intestine. III The influence of the pituitary-adrenal system on the differentiation of phosphatase in the duodenum of the suckling mouse. J Exp Zool 124:329-346

35. Yeh K. Moog F 1974 Intestinal lactase activity in the suckling rat: influence of hypophysectomy and thyroidectomy. Science 183:77-79

36. Koldovsky O 1981 Role of nutritional, hormonal and intrinsic factors in expression of normal perinatal development pattern of intestinal disaccharidases in mammals. In: Lebenthal E (ed) Textbook of Gastroenterology and
Nutrition in Infancy. Raven Press, New York, pp 77-82

37. Trier JS, 1968 Morphology of the epithelium of the small intestine. In: Code CF (ed) Handbook of Physiology, Sect 6, Vol 3, American Physiological Society, Washington, DC, pp 1125-1150

38. Nordstrom C, Dahlquist A, Josefson L 1968 Quantitative determination of enzyme in different parts of the villi and crypts of the small intestine. Comparison of alkaline phosphatase, disaccharidases and dipeptidases. $\mathbf{J}$ Histochem Cytochem 15:713-721

39. Tsuboi KK, Kwong LK, Neu J, Sunshine P 1981 A proposed mechanism of normal intestinal lactase decline in the postweaned mammal. Biochem Biophys Res Comm 101:645-652 